\title{
Proteomic study of sporadic inclusion body myositis
}

\author{
Ke Li' ${ }^{1}$ Chuanqiang $\mathrm{Pu}^{2 *}$, Xusheng Huang ${ }^{2}$, Jiexiao Liư ${ }^{2}$ Yanling Mao ${ }^{2}$ and Xianghui Lu
}

\begin{abstract}
Background: Sporadic inclusion body myositis (s-IBM) is the most commonly occurring acquired inflammatory myopathy in elderly people (>45 years); however, pathogenic mechanisms are poorly understood and diagnostic tools are limited. In view of this, new therapeutic and diagnostic molecular markers for s-IBM need to be identified.

Experimental design: In this study, the proteomes from three s-IBM cases were compared with those from three cases of neurogenic muscular atrophy (control). Proteins were separated by 2-dimensional polyacrylamide gel electrophoresis and profiled by mass spectrometric sequencing and subsequently validated by western blot.

Results: Differential expression was noted in 29 proteins (16 upregulated and 13 downregulated) in s-IBM compared with the control group. Functions of these proteins include oxidative stress response, regulation of apoptosis, signal transduction, and cytoskeleton. Expression of both amyloid precursor protein (APP) and aB-crystallin was increased in s-IBM cases.

Conclusions: Our study reveals a unique pattern of protein expression in s-IBM, which should be further investigated in a wider cohort of IBM patients to fully realize the potential diagnostic or therapeutic benefits.
\end{abstract}

Keywords: APP, aB-crystallin, Neurogenic muscular atrophy, Sporadic inclusion body myositis

\section{Background}

Sporadic inclusion body myositis (s-IBM) is a sporadic inflammatory muscle disease that occurs most frequently in middle-aged and elderly individuals [1]. There is considerable debate as to whether the pathogenesis of s-IBM is a T cell mediated autoimmune myopathy, or a myodegenerative disorder of undetermined type with a secondary inflammatory component [2]. Moreover, an effective treatment for s-IBM does not exist; thus, current research efforts are focused on identifying molecular markers for this disease.

Until now no proteomic studies on s-IBM muscular tissue have been carried out in China. Here, we investigated the proteome of s-IBM muscular tissue with the goal of finding specific protein markers closely associated with development and morbidity of s-IBM, which in turn may provide new clues for the pathogenesis of the disease.

\footnotetext{
* Correspondence: pucq30128@sina.cn

2Department of Neurology, Chinese PLA General Hospital, 28 Fuxing Road, Beijing 100853, China

Full list of author information is available at the end of the article
}

\section{Results and discussion}

Clinical characteristics of the cases with s-IBM are summarized in Table 1. The involved muscles included quadriceps femoris, iliopsoas, finger flexor muscles, biceps brachii, tibialis anterior, and deltoid. CK levels in the serum of the patients were $384 \mathrm{IU} / \mathrm{L}, 234 \mathrm{IU} / \mathrm{L}$, and $445 \mathrm{IU} / \mathrm{L}$, respectively. Biopsy sites of the patients were biceps brachii or quadriceps femoris, whereas biceps brachii was used for the normal tissue specimens. Pathological examination showed that atrophic muscle fibers were angular, irregular, and round, with muscle fiber hypertrophy. Fimbriated cavity and sand-like particles inclusion bodies were shown in the atrophic muscle fibers. Non-necrotic muscle fibers were infiltrated by monocytes (Figure 1).

IPG dry adhesive tape $(18 \mathrm{~cm}, \mathrm{pH} 3-10)$ was used in the first dimension of electrophoresis, while gel porosity was $13 \%$ and the molecular weight gradient was $14-97 \mathrm{kDa}$ in the second phase (Figure 2). These parameters resulted in clear protein separation, and uniformity of protein distribution. Each sample was subjected to electrophoresis twice, with protein spots in the duplicate maps demonstrating good reproducibility and stability. The average matching rate was as high as $85.1 \%$, and the number of detected matching protein spots was 1052. Using ImageMaster 2D 
Table 1 Clinical characteristics of the cases with s-IBM

\begin{tabular}{lllllllll}
\hline Cases & Sex & Age at onset & Duration(year) & Symptoms at onset & Involved muscles & CK (IU/L) & EMG & Biopsy site \\
\hline 1 & Male & 52 & 2.5 & Weakness of both upper limbs & Qua, Bi, Fin, Del & 384 & Myogenic & Bi \\
2 & Female & 60 & 1.2 & Weakness of both lower limbs & Qua, Bi, Fin & 234 & Myogenic & Qua \\
3 & Male & 51 & 3 & Weakness of right lower limb & Qua, Bi, Fin, llio, TA & 445 & Myogenic & Bi \\
\hline
\end{tabular}

Qua: quadriceps femoris; llio: iliopsoas; Fin: finger flexor muscles; Bi: biceps brachii; TA: tibialis anterior; Del: deltoid.

Platinum software, 29 differential protein spots were determined to have significant changes compared with controls $(P<0.05)$. Of these, 16 proteins showed increased expression in s-IBM, while the remaining 13 showed decreased expression.

The 29 proteins with differential expression were chosen from the s-IBM group and subjected to MALDI-TOF-MS analysis post trypsin-digestion. A representative electrophoretogram of peptide mass from Spot 9 is presented in Figure 3. Proteins were identified using the Mascot database (Table 2).

Entrez Gene IDs of the differentially expressed proteins were submitted on-line to the DAVID network station (National Institutes of Health (NIH)), and the biological functions of these proteins were classified using the Functional Annotation tool. The major biological functions included cytoskeleton organization, muscle contraction, regulation of muscle contraction, oxidative stress response, maintenance of homeostasis, regulation of apoptosis, and local adherence. Of these functional categories, 10 of the 29 proteins were involved in cytoskeleton organization, 7 participated in regulating apoptosis, and 5 proteins played a role in peroxidation (Table 3 ). We analyzed the KEGG signaling pathway, and found that the differentially expressed proteins were involved in a total of 19 signaling pathways (Table 4).

By integrating bioinformatics analysis and literature search results, we selected APP and $\alpha B$-crystallin from the differentially expressed proteins for further analysis via Western Blot. These results confirmed that expression levels of APP and $\alpha \mathrm{B}$-crystallin protein were increased in $\mathrm{s}$-IBM tissue relative to normal muscle, validating our $2 \mathrm{D}$ proteome dataset. (Figure 4, Table 5).

Relative expression levels of $\alpha \mathrm{B}$-crystallin and APP mRNA in tissue from the s-IBM group were shown in Table 6. Similar to the results for protein levels, relative mRNA expression levels of both $\alpha B$-crystallin and APP in the s-IBM group were significantly increased $(\mathrm{P}<0.05)$.

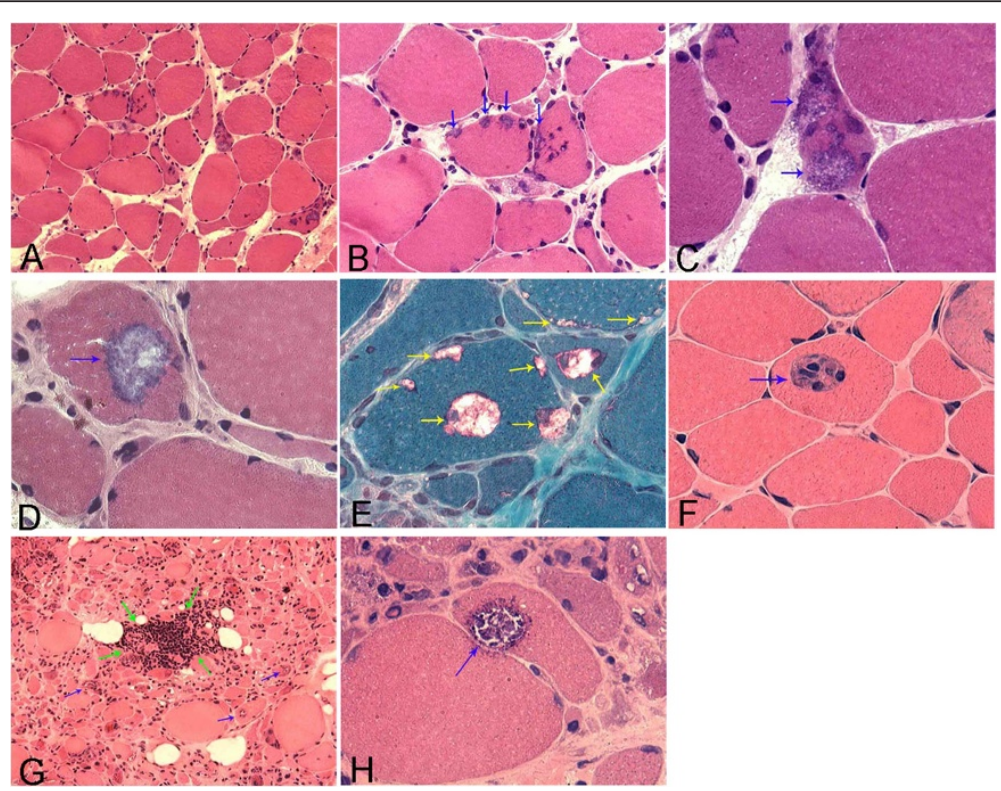

Figure 1 Pathological characteristics of sporadic inclusion body myositis (s-IBM). A-C: Case 1, atrophic muscle fibers were angular, irregular, and round, with muscle fiber hypertrophy, HE staining, $\times 100$ (A); Fimbriated cavity and inclusion bodies (blue arrows), HE staining, $\times 200$ (B); Sand-like particles (inclusion bodies) (blue arrows), HE staining, $\times 400$ (C). D F: Case 2, round Fimbriated cavities in the atrophic muscle fibers, with sand-like inclusion bodies in which (blue arrows), HE staining, $\times 400$ (D); Red particles of inclusion bodies in fimbriated cavities (yellow arrows), Gomori staining, $\times 400$ (E); Nonnecrotic muscle fibers infiltrated by monocytes (blue arrows), HE staining, $\times 200$ (F). G H: Case 3, Focal inflammatory infiltration (green arrows) and fimbriated cavities showed in several muscle fibers (blue arrows), HE staining, $\times 100$ (G); Round fimbriated cavities in atrophic muscle fibers, with gross particles of inclusion bodies in which (blue arrows), HE staining, $\times 400(\mathbf{H})$. 

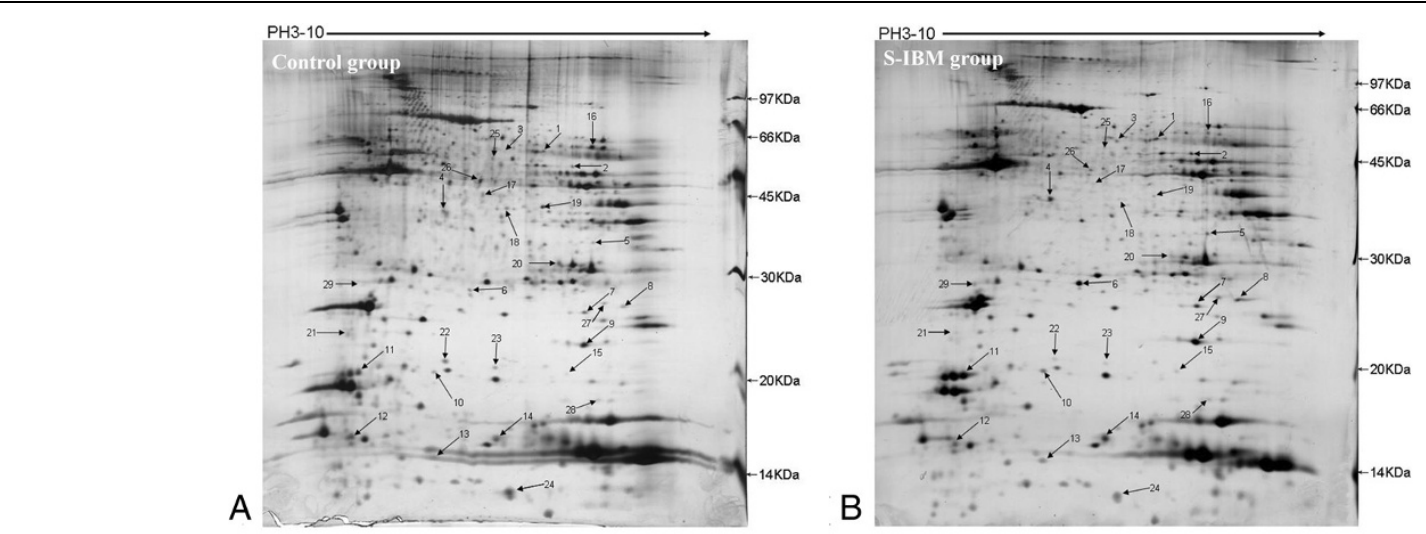

Figure 2 Two-dimensional electrophoresis of muscle tissue from control group (A) and s-IBM patients (B). Arrows represent the protein spots with significant differences in relative intensity, identified by t-test. The protein spots with significant differences in expression are numbered \#1-29.

The myodegenerative disease s-IBM is common in senile patients, and it is thought that ageing associated accumulation and sedimentation of proteins in intracellular environment plays a role in the disease pathogenesis $[1,2]$. Oxidative stress and stress reaction in endoplasmic reticulum also contribute to the disease pathogenesis. The above factors cumulatively lead to progressive degeneration and necrosis of muscle $[1,2]$. It was initially believed that s-IBM was a disease involving abnormal protein conformation, inclusive of unfolding and mis-folding of many proteins in muscle cells, which in turn induced cytotoxicity and abnormal accumulation of many proteins $[3,4]$. Therefore, investigation of proteins with differential expression during pathogenesis of s-IBM will provide the foundation for further revealing the pathological mechanisms of sIBM. Proteomics can be used to screen a great quantity of differential protein spots in the target tissue, which will provide technical support for analysis of proteins with differential expression.

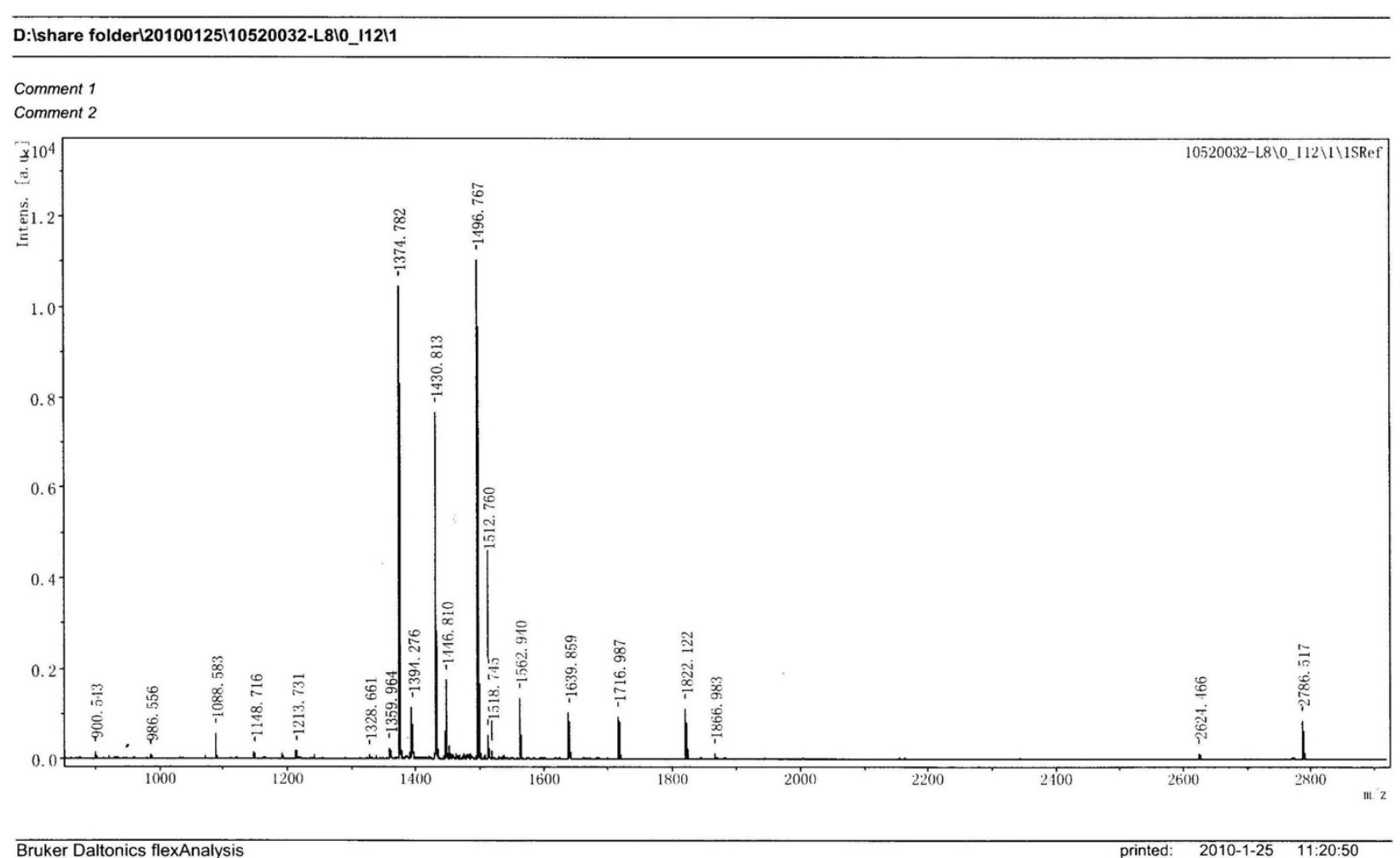

Figure 3 Representative electrophoretogram of peptide mass of Spot 9. 
Table 2 Search results of proteins with differential expression using Mascot database

\begin{tabular}{|c|c|c|c|c|c|c|}
\hline $\begin{array}{l}\text { Spot } \\
\text { No. }\end{array}$ & Protein name & Score* & Chromosome & NCBI index & Expression & Function \\
\hline 1 & $\begin{array}{l}\text { Aldehyde dehydrogenase } 1 \text { family, } \\
\text { member } A 1\end{array}$ & 141 & $9 q 21.13$ & gi|21361176 & $\uparrow$ & Oxidation reduction \\
\hline 2 & Enolase 1, (alpha) & 218 & 1p36.3-p36.2 & gi|4503571 & $\uparrow$ & Negative regulation of cell growth \\
\hline 3 & Amyloid beta A4 protein precursor & 80 & $21 \mathrm{q} 21.2 ; 21 \mathrm{q} 21.3$ & gi|4502167 & $\uparrow$ & Neuron apoptosis, ion binding \\
\hline 4 & Troponin T type 1 (skeletal, slow) & 165 & $19 q 13.4$ & gi|187173290 & $\uparrow$ & Troponin T binding, muscle contraction \\
\hline 5 & Voltage-dependent anion channel 2 & 130 & $10 q 22$ & gi|55664661 & $\uparrow$ & Ion channel activity \\
\hline 6 & $\begin{array}{l}\text { Myosin, light chain } 6 \mathrm{~B} \text {, alkali, smooth } \\
\text { muscle and non-muscle }\end{array}$ & 230 & $12 q 13.13$ & gi|4505303 & $\uparrow$ & Muscle contraction \\
\hline 7 & Superoxide dismutase 2, mitochondrial & 127 & $6 q 25.3$ & gi|67782305 & $\uparrow$ & Antioxidant activity \\
\hline 8 & Peroxiredoxin 1 & 230 & $1 \mathrm{p} 34.1$ & gi|4505591 & $\uparrow$ & Oxidoreductase activity \\
\hline 9 & Crystallin, alpha B & 172 & $11 q 22.3-q 23.1$ & gi|4503057 & $\uparrow$ & Response to reactive oxygen species \\
\hline 10 & Heat shock protein, alpha-crystallin-related, B6 & 70 & $19 q 13.12$ & gi|21389433 & $\uparrow$ & Response to temperature stimulus \\
\hline 11 & Myosin, light chain 2, regulatory, cardiac, slow & 248 & $12 q 24.11$ & gi|94981553 & $\uparrow$ & Regulation of muscle contraction \\
\hline 12 & Cytochrome c oxidase subunit Va & 61 & $15 q 24.1$ & gi|190885499 & $\downarrow$ & Oxidation reduction \\
\hline 13 & S100 calcium binding protein A13 & 76 & $1 q 21$ & gi|62632859 & $\uparrow$ & Calcium ion binding \\
\hline 14 & Fatty acid binding protein 3 & 147 & 1p33-p32 & gi|4758328 & $\uparrow$ & Lipid transporter activity \\
\hline 15 & Transgelin & 164 & $11 q 23.2$ & gi|48255905 & $\uparrow$ & Actin binding \\
\hline 16 & Fibrinogen beta chain & 280 & $4 q 28$ & gil70906435 & $\downarrow$ & $\begin{array}{l}\text { Cell activation, protein complex } \\
\text { assembly }\end{array}$ \\
\hline 17 & Myosin heavy chain lla & 125 & 17p13.1 & gi|153791586 & $\downarrow$ & Muscle contraction \\
\hline 18 & Enolase 3 (beta, muscle) & 72 & 17pter-p11 & gi|119610782 & $\downarrow$ & $\begin{array}{l}\text { Phosphopyruvate hydratase activity, } \\
\text { skeletal muscle regeneration }\end{array}$ \\
\hline 19 & Troponin T3, skeletal, fast isoform 2 & 111 & $11 \mathrm{p} 15.5$ & gi|112789538 & $\downarrow$ & Muscle contraction \\
\hline 20 & Carbonic anhydrase I & 80 & $8 q 13-q 22.1$ & gi|4502517 & $\downarrow$ & $\begin{array}{l}\text { Carbonate dehydratase activity, ion } \\
\text { binding }\end{array}$ \\
\hline 21 & Uridine monophosphate synthetase & 68 & $3 q 13$ & gi|197210454 & $\downarrow$ & $\begin{array}{l}\text { Pyrimidine nucleoside metabolic } \\
\text { process }\end{array}$ \\
\hline 22 & $\begin{array}{l}\text { Adaptor-related protein complex } 3, \text { mu } 2 \\
\text { subunit }\end{array}$ & 127 & $8 p 11.2$ & gi|5803000 & $\downarrow$ & Protein transport \\
\hline 23 & Haptoglobin-related protein & 60 & $16 q 22.1$ & gi|296653 & $\downarrow$ & Proteolysis \\
\hline 24 & Hemoglobin beta & 106 & $11 \mathrm{p} 15.5$ & gi|75491671 & $\downarrow$ & Oxygen transporter activity \\
\hline 25 & Albumin & 141 & $4 q 11-q 13$ & gi|27692693 & $\downarrow$ & $\begin{array}{l}\text { Response to starvation, antioxidant } \\
\text { activity }\end{array}$ \\
\hline 26 & Myosin, heavy chain 7, cardiac muscle, beta & 122 & $14 q 12$ & gi|386973 & $\downarrow$ & Muscle contraction \\
\hline 27 & Troponin I type 1 (skeletal, slow) & 162 & $1 \mathrm{q} 31.3$ & gi|14787427 & $\downarrow$ & Regulation of muscle contraction \\
\hline 28 & Chain A, Human peroxiredoxin 5 & 114 & $11 q 13$ & gi|6912238 & $\uparrow$ & Oxidoreductase activity \\
\hline 29 & Rho GDP dissociation inhibitor (GDI) alpha & 83 & $17 q 25.3$ & gi|4757768 & $\uparrow$ & Small GTPase regulator activity \\
\hline
\end{tabular}

*Mascot score (Mascot score $>65 ; P<0.05$, the P-value has been generated by the DAVID algorithm and were adjusted for multiple comparisons).

Hutchinson et al. (2008) did not find either distinctive expression or lack of protein expression between five cases of normal muscle tissues and six cases of IBM muscle tissues [5]. Of note though, the analyses was essentially based on present/absent criteria since the intensity of the protein spots were not analyzed in details, as in the current study, to detect differential expression of proteins, if any [5]. In the current study the electrophoretograms had good stability and reproducibility; in addition, the protein spots in the two electrophoretograms of the same sample showed good stability and reproducibility, and the average match rate was $85.1 \%$. This allowed us to further analyze, based on the intensity of the spots, the differentially expressed proteins between IBM tissues and normal tissues. In a separate study, $\mathrm{Li} \mathrm{J}$ et al. (2006) had compared the 2D electrophoresis results of four cases of IBM muscle tissues and five cases of muscle tissues of other myositis, and found that APP was one of 
Table 3 Major functions of proteins with differential expression

\begin{tabular}{|c|c|c|c|}
\hline Function annotation & $\begin{array}{l}\text { Gene } \\
\text { number }\end{array}$ & Spot No. & P-value \\
\hline \multicolumn{4}{|l|}{ Biology process } \\
\hline Muscle contraction & 9 & $\begin{array}{l}9,17,26,6,4,19 \\
10,27,11\end{array}$ & $1.1 \mathrm{E}-5$ \\
\hline Cytoskeleton & 10 & $\begin{array}{l}29,3,9,17,26,11 \\
6,4,19,27\end{array}$ & $3.9 \mathrm{E}-4$ \\
\hline Regulation of apoptosis & 7 & $29,25,3,9,8,28,7$ & $4.4 \mathrm{E}-3$ \\
\hline $\begin{array}{l}\text { Negative regulation of } \\
\text { apoptosis }\end{array}$ & 5 & $29,25,9,28,7$ & $5.0 \mathrm{E}-3$ \\
\hline $\begin{array}{l}\text { Response to reactive } \\
\text { oxygen species }\end{array}$ & 5 & $9,26,8,28,7$ & $1.4 \mathrm{E}-5$ \\
\hline $\begin{array}{l}\text { Regulation of muscle } \\
\text { contraction }\end{array}$ & 5 & $11,27,4,19,10$ & $3.9 \mathrm{E}-4$ \\
\hline Cellular homeostasis & 5 & $3,23,8,28,7$ & $1.3 \mathrm{E}-2$ \\
\hline $\begin{array}{l}\text { Cytoskeleton-dependent } \\
\text { intracellular transport }\end{array}$ & 4 & $3,17,26,6$ & $1.5 \mathrm{E}-4$ \\
\hline Stress-activated MAPK cascade & 2 & 9,8 & $2 \mathrm{E}-4$ \\
\hline \multicolumn{4}{|l|}{ Molecular function } \\
\hline Cytoskeletal protein binding & 8 & $\begin{array}{l}9,17,26,11,15,27 \\
4,19\end{array}$ & 4.4E-5 \\
\hline Pyrophosphatase activity & 5 & $17,11,6,26,19$ & $2.0 \mathrm{E}-2$ \\
\hline Oxidoreductase & 5 & $1,12,8,28,7$ & $8.5 \mathrm{E}-3$ \\
\hline Antioxidant activity & 4 & $25,8,28,7$ & $1.1 \mathrm{E}-4$ \\
\hline Glucose metabolic process & 3 & $9,2,18$ & 3.7E-2 \\
\hline $\begin{array}{l}\text { Phosphopyruvate hydratase } \\
\text { activity }\end{array}$ & 2 & 18,2 & $1.0 \mathrm{E}-2$ \\
\hline Focal adhesion & 2 & 17,26 & $1.2 \mathrm{E}-2$ \\
\hline
\end{tabular}

Table 3 represent a list of KEGG associated to single protein changed in sIBM, related enriched protein are reported in Table 2, but are not consistent. For example, for proteins 11, 12, 26 associated to muscle contraction signal pathway, 11 and 26 are also reported in Table 2 (proteins associated to biological function of muscle contraction). For 11, 17, 26 associated to Tight junction signal pathway, 17 and 26 are also reported in Table 2 (proteins associated to biological function of focal adhesion).

the upregulated proteins in sIBM cases [6]. In comparison, we compared differential expression between IBM and normal muscle tissues and also found APP to be upregulated in sIBM cases. In addition, we also found $\alpha B$ crystallin to be upregulated in these cases. APP is closely related to abnormal accumulation and mis-folding of proteins, whereas $\alpha \mathrm{B}$-crystallin is related to protein folding, hence suggesting a direct role of these proteins in the pathogenesis of sIBM.

Functional fuzzy grouping analysis was performed using the Functional Annotation tool supplied by the DAVID network. It was found that these proteins primarily participated in the cellular peroxidation response to stress, apoptosis regulation, signal transduction, and skeletal muscle contraction. Based on these major biological functions, the differentially expressed proteins can be classified as followed.
Table 4 Summary of proteins with differential expression participated in KEGG signal pathway

\begin{tabular}{|c|c|c|}
\hline KEGG pathway & $\begin{array}{l}\text { Gene } \\
\text { number }\end{array}$ & Spot No. \\
\hline Muscle contraction & 3 & $12,26,11$ \\
\hline Tight junction & 3 & $17,26,11$ \\
\hline Huntington's disease & 3 & $12,7,5$ \\
\hline Parkinson's disease & 3 & 12,5 \\
\hline Alzheimer's disease & 2 & 3,12 \\
\hline Glycolysis/Gluconeogenesis, RNA degradation & 2 & 2,18 \\
\hline Neurotrophin signaling pathway & 1 & 29 \\
\hline Lysosome & 1 & 22 \\
\hline Retinol metabolism & 1 & 1 \\
\hline Nitrogen metabolism & 1 & 20 \\
\hline Oxidative phosphorylation & 1 & 12 \\
\hline PPAR signaling pathway & 1 & 14 \\
\hline Complement and coagulation cascades & 1 & 16 \\
\hline Focal adhesion & 1 & 11 \\
\hline Leukocyte transendothelial migration & 1 & 11 \\
\hline Regulation of actin cytoskeleton & 1 & 11 \\
\hline Vascular smooth muscle contraction & 1 & 6 \\
\hline Pyrimidine metabolism & 1 & 21 \\
\hline Calcium signaling pathway & 1 & 5 \\
\hline
\end{tabular}

Proteins participating in oxidative stress responses include superoxide dismutase (SOD), peroxydase 1, $\alpha \mathrm{B}$ crystallin, the $\mathrm{H}$-chain 7 of myoglobulin, the A- chain of peroxydase 5 , and cytochrome $\mathrm{C}$ oxidase. $\alpha \mathrm{B}$-crystallin is a member of the small heat shock protein (HSP) family [7]. Additionally, it is expressed in many tissues, with particularly high levels found in cells with low rates of mitotic division, such as those found in crystalline lens, cardiac muscle, and skeletal muscle. It was reported that as a molecular chaperone protein, $\alpha \mathrm{B}$-crystallin mainly interacts with unfolded proteins, which inhibits coalescence and thus prevents accumulation of defective proteins [8]. It has also been found that in addition to functioning as a chaperone, $\alpha \mathrm{B}$-crystallin also played a role in inhibiting apoptosis under certain circumstances $[9,10]$. Previous work demonstrated that high expression of $\alpha B$-crystallin was correlated with degenerative diseases, such as Alexander's disease [11], Alzheimer's disease (AD) [12], amyotrophic lateral sclerosis [13], Pick's disease [14], Creutzfeldt-Jakob disease [15], and multiple sclerosis [16]. Our study showed increased expression of $\alpha B$-crystallin in s-IBM, which indicated that this protein may be involved in the pathogenesis of s-IBM.

Proteins involved in regulation of apoptosis include amyloid precursor protein, SOD, peroxydase $1, \alpha B$-crystallin, albumin, A-chain of peroxidase 5, and Rho GDP dissociation inhibiting factor- $\alpha$. Amyloid precursor protein and 


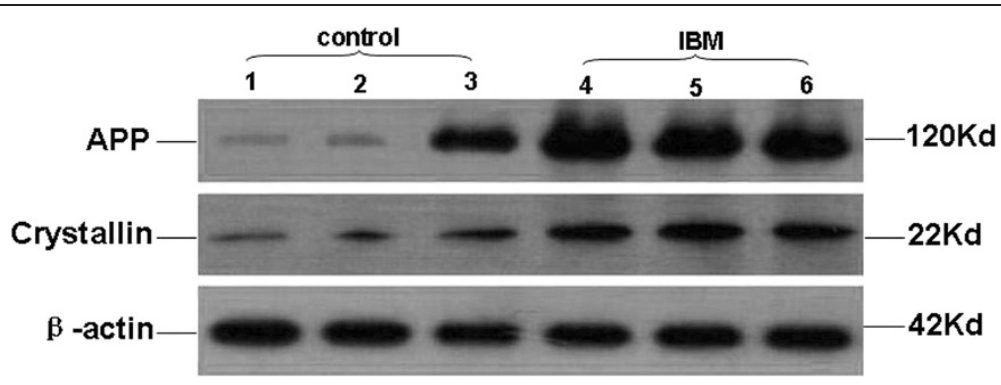

Figure 4 Western blot of aB-crystallin and amyloid precursor protein expression in s-IBM. Through semi-quantitative analysis using gray-scale quantification, steady-state expression levels of aB-crystallin and APP in s-IBM were found to be significantly increased relative to controls $(P<0.05)$.

$\beta$-actin was used as an internal control, and protein expression was normalized by taking the target protein/ $\beta$-actin.

peroxydase1 play a role in promoting apoptosis, while the others are involved in inhibiting apoptosis. Except for albumin, expression levels of the other four inhibitory proteins were increased. We hypothesize that while the organism activates anti-apoptosis mechanisms during progression of s-IBM, apoptotic activity cannot be fully suppressed, thereby leading to further development of the disease.

APP has been identified as the major protein in the plaques of senile AD patients [17], and mutation of this gene is considered an important etiological factor of AD. Our study showed by quantitative analysis that expression of APP protein, as well as mRNA, is increased in s-IBM patients, suggesting that APP participates in the pathophysiological progress of abnormal deposition into inclusion bodies. APP can induce endoplasmic reticulum stress (ERS), which subsequently induces the unfolded protein response (UPR). Schmidt et al. (2008) had shown that even though all inflammatory myopathies displayed ubiquitous overexpression of degeneration-associated markers, only in sIBM, expression of APP transcripts were significantly and routinely correlated with inflammation in the muscle [18]. Furthermore, in sIBM, IHC analysis revealed that inflammatory mediators including IL-1 beta co-localized to beta-amyloid depositions within myofibres [18]. In fact, within human myotubes, an upregulation of APP with subsequent intracellular aggregation of beta-amyloid was observed following exposure to interleukin (IL)-1 beta [18], suggesting that production of high amounts of pro-inflammatory mediators in sIBM muscles specifically induces betaamyloid-associated degeneration. The same correlation was observed in another separate study where it was shown that alphaB-crystallin is associated with overexpression of APP in sIBM muscle and that upregulation

Table 5 Western blot results

\begin{tabular}{llll}
\hline Group & $\mathbf{n}$ & $\mathbf{a B}-$ crystallin/ $\boldsymbol{\beta}$-actin & APP/ $\boldsymbol{\beta}$-actin \\
\hline s-IBM & 3 & $84.31 \pm 8.29^{*}$ & $204.1 \pm 12.43^{*}$ \\
Normal control & 3 & $22.27 \pm 15.75$ & $48.64 \pm 69.67$ \\
\hline
\end{tabular}

${ }^{*}$ Compared with normal control group, $P<0.05$. of alphaB-crystallin precedes accumulation of beta-amyloid [19]. Our study also supports the decade old hypothesis that in IBM muscle, pro-inflammatory cytokines secreted by immune system cells results in APP production by myofibres, and APP production by myofibres results in a feed-forward feedback loop resulting in inflammatory cytokine secretion by immune cells [20], highlighting that cell stress, inflammation and degeneration all contribute to the pathogenesis sIBM. Cumulatively, the aforementioned observations collaborate our current findings and convincingly shows that $\beta$-amyloid protein in sIBM patient muscle sample is not an artifact as occasionally debated [21]. It is plausible that APP induces ERS and UPR, which in turn enhance $\alpha \mathrm{B}$-crystallin expression and subsequent formation of soluble neurotoxic oligomers [22].

During analysis of the KEGG pathway, we found proteins with altered expression levels that are components of 19 pathways. The tight junction pathway, muscle contraction, and Huntington's and Parkinson's disease pathways had the most hits. Aside from these, however, using functional analysis we found that peroxydase 1 and $\alpha \mathrm{B}$-crystallin are correlated with the activation of mitogen-activated protein kinase (MAPK), which is primarily involved in regulating cell growth. We surmise that the two proteins regulate the strength of upstream signaling of the MAPK pathway, thus playing an indirect role in regulating cell growth during interactions with molecules such as oxidative stress or extracellular growth factors.

DAVID functional analysis showed that the proteins with different expression patterns in s-IBM participating in regulation of muscle contraction were subunit 1 of troponin $\mathrm{T}, \alpha \mathrm{B}$ related HSP, myoglobulin L-chain 2, troponin T3, and troponin I. Expression levels of troponin T3 and troponin I were decreased in s-IBM samples, while

Table 6 RT-PCR results

\begin{tabular}{llll}
\hline Group & $\mathbf{n}$ & aB-crystallin/ $\boldsymbol{\beta}$-actin & APP/ $\boldsymbol{\beta}$-actin \\
\hline sIBM & 3 & $2.27 \pm 0.81^{*}$ & $4.29 \pm 1.15^{*}$ \\
Normal control & 3 & $0.92 \pm 0.12$ & $1.24 \pm 0.63$ \\
\hline
\end{tabular}

${ }^{*}$ Compared with normal control group, $P<0.05$. 
the other proteins were increased. This result suggests that regulation of muscle contraction is increased during the development of inclusion body myositis.

One limitation of the current study is the small sample size analyzed. This necessitates verification of our findings in a larger cohort of IBM patients, in isolation and in comparison to other myopathy and normal controls.

\section{Conclusions}

In summary, 29 proteins exhibiting differential expression levels in S-IBM were screened in our study. Some of these proteins have not been reported previously. The functions of these proteins include oxidative stress, regulation of apoptosis, signal transduction, and cytoskeleton. Further research into muscle diseases using proteomic methods may provide important clues for better understanding of the pathogenesis of these diseases, and help with more accurate diagnosis.

\section{Methods}

\section{Patient inclusion criteria and sample collection}

All patients provided signed informed consent, and the study was approved by the Institutional Review Board. We used the European Neuromuscular Centre (ENMC) (2011) diagnostic criteria for diagnosis of IBM and subsequent inclusion in the current study. All the included patients met the diagnostic criteria for 'clinically defined IBM'. The clinical features were duration of weakness > 12 months, creatine kinase $(\mathrm{CK}) \leq 15 \mathrm{x}$ ULN (upper limit of normal), age at onset $>45$ years, finger flexion weakness $>$ shoulder abduction weakness, and knee extension weakness $\geq$ hip flexor weakness. The histopathological features associated with one or more, but not all of endomysial inflammatory infiltrate, upregulation of MHC class I, rimmed vacuoles, protein accumulation or $15-18 \mathrm{~nm}$ filaments. Samples of inclusion body myositis (IBM) were chosen from three IBM patients who first visited the clinic service of our hospital. Biopsy specimens of biceps or quadriceps muscle tissue were selected based on electromyogram results, then washed with saline. Three cases, who first came to our clinic for weak limb and finally pathologically identified as neurogenic muscular atrophy (NMA) by electromyography and normal tissue by muscle biopsy, served as the control group. After blotting of excess saline with filter paper, the tissues were stored at $-80^{\circ} \mathrm{C}$.

\section{Whole protein extraction}

Preserved muscle preparations were prepared and washed with phosphate buffered saline (PBS) to remove adherent hemoglobin and other contaminating proteins resulting from haematolysis during specimen collection. Subsequently, tissue was homogenized in protease inhibitorcontaining lysis buffer ( $40 \mathrm{mM}$ Tris- $\mathrm{HCl}, 7 \mathrm{M}$ urea, $2 \mathrm{M}$ sulfourea, $4 \%$ CHAPS, 1\% DTT, and 1 mM EDTA) at a ratio of 50:1 (buffer: tissue). DNase $(10 \mu \mathrm{g} / \mu \mathrm{l})$ and RNase $(5 \mu \mathrm{l})$ were added. Samples were incubated on ice for $20 \mathrm{~min}$, followed by centrifugation at $14000 \mathrm{r} / \mathrm{min}$ at $4^{\circ} \mathrm{C}$ for $20 \mathrm{~min}$. The supernatant which containing the whole protein of muscle was collected and the concentration of total protein was normalized for the subsequent assay.

\section{Two-dimensional gel electrophoresis}

Isoelectric focusing electrophoresis was performed with an Ettan IPGphor IEF System (GE Healthcare, U.S.). Before detection, protein samples were centrifuged for $2 \mathrm{~min}$, then $100 \mu \mathrm{g}$ of sample was dissolved in $800 \mu \mathrm{l}$ of rehydration buffer (8 M urea, 0.02\% CHAPS, $0.02 \mathrm{M}$ DTT, and $0.05 \%$ IPG buffer). For first dimension electrophoresis, $18 \mathrm{~cm}$ solid phase $\mathrm{pH}$ gradient $(\mathrm{pH} 3-10)$ dry adhesive tape was rehydrated for $16 \mathrm{~h}$ at $21^{\circ} \mathrm{C}$, and $20 \mu \mathrm{L}$ of sample supernatant was added. Electrophoresis was performed for $15 \mathrm{~h}$ at $0-3500 \mathrm{~V}$, followed by electrophoresis for $6.3 \mathrm{~h}$ at $3500 \mathrm{~V}$. The focus adhesive tape was balanced twice in SDS balanced solution, and then agitated in a rocking bed for $2 \times 15 \mathrm{~min}$. The adhesive tape was removed for the second phase of vertical SDS-PAGE, with continuous flow at $40 \mathrm{~mA}$ for $40 \mathrm{~min}$, and $60 \mathrm{~mA} 5 \mathrm{~h}$ until the leading edge of bromochlorophenol blue reached the bottom of glass plate. Following completion of electrophoresis, coomassie brilliant blue staining was carried out. The 2D gel image was analyzed by ImageMaster 2D Platinum software; analysis and adjustments included intensity correction, spot detection, and background reduction.

\section{Enzymolysis and mass-spectrum identification and alignment}

Differential protein particles were cut from the gel for trypsin digestion. The extracted peptides were dissolved in $0.1 \%$ TFA/ $\alpha$-cyano-4-hydroxy-cinnamic acid groundmass, and samples were applied to the target plate. ABI Voyager DE Pro was used for MALDI-TOF/MS analysis. Database queries were carried out via SwissProt, UniProt, and NCBInr on http://prospector.ucsf.edu/prospector/cgi-bin/msform.cgi? form=msfitstandard and http://www.matrixscience.com/.

\section{Western blotting and RT-PCR}

Western blotting and RT-PCR were performed following standard procedures. Anti-APP monoclonal antibody (1:500; Santa Cruz Biotechnology), anti- $\alpha$ B-crystallin polyclonal antibody (1:1,000; Abcam) were used as an internal loading control.

\section{Statistical analysis}

Statistical analysis was performed using SPSS 13.0. Data was represented as mean \pm standard deviation (SD). Unpaired $t$ test was used to compare groups, $\mathrm{P}<0.05$ was considered statistically significant. 


\section{Competing interests}

The authors declared that they have no competing interest.

\section{Authors' contributions}

$\mathrm{KL}$ interpreted data and drafted the manuscript. CP contributed to conception and design. $\mathrm{XH}, J \mathrm{~L}, \mathrm{YM}, \mathrm{XL}$ performed acquisition of data, analysis and interpretation of data. All authors read and approved the final manuscript.

\section{Author details}

${ }^{1}$ Department of Geriatric Neurology, Chinese PLA General Hospital, Beijing 100853, China. ${ }^{2}$ Department of Neurology, Chinese PLA General Hospital, 28 Fuxing Road, Beijing 100853, China.

Received: 26 March 2014 Accepted: 13 August 2014

Published online: 12 September 2014

\section{References}

1. Needham M, Corbett A, Day T, Christiansen F, Fabian V, Mastaglia F: Prevalence of sporadic inclusion body myositis and factors contributing to delayed diagnosis. J Clin Neurosci 2008, 15:1350-1353.

2. Needham M, Mastaglia FL: Inclusion body myositis: current pathogenetic concepts and diagnostic and therapeutic approaches. Lancet Neurol 2007, 6:620-631.

3. Oldfors A, Moslemi AR, Jonasson L, Ohlsson M, Kollberg G, Lindberg C: Mitochondrial abnormalities in inclusion-body myositis. Neurology 2006, 66:S49-S55.

4. Askanas $V$, Engel WK: Inclusion-body myositis: a myodegenerative conformational disorder associated with $A \beta$, protein-misfolding and proteasome inhibition. Neurology 2006, 66:S39-S48.

5. Hutchinson DO, Jongbloed B: Two-dimensional gel electrophoresis in inclusion body myositis. J Clin Neurosci 2008, 15:440-444.

6. Li J, Yin C, Okamoto H, Jaffe H, Oldfield EH, Zhuang Z, Vortmeyer AO, Rushing EJ: Proteomic analysis of inclusion body myositis. J Neuropathol Exp Neurol 2006, 65:826-833.

7. Kato K, Shinohara H, Kurobe N, Goto S, Inaguma Y, Ohshima K: Immunoreactive alpha A-crystallin in rat nonlenticular tissues detected with a sensitive immunoassay method. Biochim Biophys Acta 1991, 1080:173-180.

8. Ingolia TD, Craig EA: Four small Drosophila heat shock proteins are related to each other and to mammalian alpha-crystallin. Proc Natl Acad Sci U S A 1982, 79:2360-2364.

9. Derham BK, Harding JJ: Alpha-crystallin as a molecular chaperone. Prog Retin Eye Res 1999, 8:463-509.

10. Yu S, MacRae TH: The small heat shock proteins and their role in human disease. FEBS J 2005, 272:2613-2627.

11. Iwaki T, Kume-Iwaki A, Liem RK, Goldman JE: AlphaB-crystallin is expressed in non-lenticular tissues and accumulates in Alexander's disease brain. Cell 1989, 57:71-78.

12. Dabir DV, Trojanowski JQ, Richter-Landsberg C, Lee VM, Forman MS: Expression of the small heat-shock protein alphaB-crystallin in tauopathies with glial pathology. Am J Pathol 2004, 164:155-166.

13. Vleminckx V, Van Damme P, Goffin $K$, Delye $H$, Van Den Bosch $L$, Robberecht W: Upregulation of HSP27 in a transgenic model of ALS. J Neuropathol Exp Neurol 2002, 61:968-974.

14. Fujino Y, Delucia MW, Davies P, Dickson DW: Ballooned neurones in the limbic lobe are associated with Alzheimer type pathology and lack diagnostic specificity. Neuropathol Appl Neurobiol 2004, 30:676-682.

15. Renkawek K, De Jong WW, Merck KB, Frenken CW, Van Workum FP, Bosman GJ: Alpha B-crystallin is present in reactive glia in Creutzfeldt-Jakob disease. Acta Neuropathol 1992, 83:324-327.

16. Steinman L: A molecular trio in relapse and remission in multiple sclerosis. Nat Rev Immunol 2009, 9:440-447.

17. Woo HN, Park JS, Gwon AR, Arumugam TV, Jo DG: Alzheimer's disease and Notch signaling. Biochem Biophys Res Commun 2009, 390:1093-1097.

18. Schmidt J1, Barthel K, Wrede A, Salajegheh M, Bähr M, Dalakas MC: Interrelation of inflammation and APP in SIBM: IL-1 beta induces accumulation of beta-amyloid in skeletal muscle. Brain 2008, 131(Pt 5):1228-1240.

19. Muth IE, Barthel K, Bähr M, Dalakas MC, Schmidt J: Proinflammatory cell stress in sporadic inclusion body myositis muscle: overexpression of alphaB-crystallin is associated with amyloid precursor protein and accumulation of beta-amyloid. J Neurol Neurosurg Psychiatry 2009, 80:1344-1349.

20. Dalakas MC: Molecular immunology and genetics of inflammatory muscle diseases. Arch Neurol 1998, 55:1509-1512.

21. Greenberg SA: Comment on 'Interrelation of inflammation and APP in sIBM: IL-1beta induces accumulation of beta-amyloid in skeletal muscle'. Brain 2009, 132(Pt 4):e106.

22. Stege GJ, Renkawek K, Overkamp PS, Verschuure P, Van Rijk AF, Reijnen-Aalbers A, Boelens WC, Bosman GJ, De Jong WW: The molecular chaperone alphaBcrystallin enhances amyloid beta neurotoxicity. Biochem Biophys Res Commun 1999, 262:152-156.

doi:10.1186/s12953-014-0045-2

Cite this article as: Li et al.: Proteomic study of sporadic inclusion body

myositis. Proteome Science 2014 12:45.

\section{Submit your next manuscript to BioMed Central and take full advantage of:}

- Convenient online submission

- Thorough peer review

- No space constraints or color figure charges

- Immediate publication on acceptance

- Inclusion in PubMed, CAS, Scopus and Google Scholar

- Research which is freely available for redistribution

Submit your manuscript at www.biomedcentral.com/submit
C) BioMed Central 